\title{
Correction to: Adjudging efficacy of geonet reinforcement on the seismic performance of brick masonry structures: an experimental study
}

\author{
Susanta Banerjee $\cdot$ Sanket Nayak (D) S Sreekanta Das
}

Accepted: 10 November 2021/Published online: 15 November 2021

(C) RILEM 2021

\section{Correction to:}

Materials and Structures (2021) 54:213

https://doi.org/10.1617/s11527-021-01805-8

In this article the affiliation details for Sanket Nayak were incorrectly given as 'Department of Civil and Environmental Engineering, University of Windsor, Windsor, Canada' but should have been "Department of Civil Engineering, Indian Institute of Technology (ISM), Dhanbad, India".

The original article has been corrected.

Publisher's Note Springer Nature remains neutral with regard to jurisdictional claims in published maps and institutional affiliations.
The original article can be found online at https:// doi.org/10.1617/s11527-021-01805-8.

S. Banerjee $\cdot$ S. Nayak $(\square)$

Department of Civil Engineering, Indian Institute of Technology (ISM), Dhanbad, India

e-mail: sanket@iitism.ac.in

S. Das

Department of Civil and Environmental Engineering,

University of Windsor, Windsor, Canada 